\title{
O FIO DA MEMÓRIA NA FICÇÃO DE FRANCISCO JOSÉ VIEGAS
}

\author{
THE THREAD OF THE MEMORY IN \\ FRANCISCO JOSÉ VIEGAS' FICTION
}

Adenize Aparecida Franco ${ }^{1}$

\section{RESUMO}

Este artigo apresenta, com base na análise do romance português contemporâneo Lourenço Marques (2002), de Francisco José Viegas, algumas considerações a respeito da constituição da memória e das identidades configuradas no contexto pós-colonial que atingiu a África de língua portuguesa e pós-Revolução dos Cravos, em Portugal. Destaca-se, num primeiro momento, a verificação e catalogação de romances contemporâneos publicados em língua portuguesa nas duas últimas décadas e que estabelecem relações com a memória histórica recente de países mantidos em regimes totalitários. Subsequentemente realiza-se a análise do romance Lourenço Marques enquanto narrativa que configura tais elementos.

PALAVRAS-CHAVE: Francisco José Viegas; Romance contemporâneo; Memória.

\section{ABSTRACT}

This article presents, based on the analysis of the contemporary Portuguese novel Lourenço Marques (2002), by Francisco José Viegas, some considerations about the constitution of the memory and the identities shaped in the postcolonial context that reached Africa of Portuguese language and the post Carnation Revolution, in Portugal. It is highlighted, firstly, the verification and cataloging of contemporary novels published in Portuguese in the last two decades and that establish relations with the recent historical memory of countries held on totalitarian regimes. Following, there is the analysis of the novel Lourenço Marques as a narrative that configures such elements.

KEYWORDS: Francisco José Viegas; Contemporary novel; Memory. 


\section{NOS CAMINHOS RECENTES E TORTUOSOS DO ROMANCE CONTEMPORÂNEO}

Neste artigo, procura-se destacar parte do processo de verificação e catalogação de romances contemporâneos publicados em língua portuguesa nas duas últimas décadas e que estabelecem relações com a memórica histórica recente de países mantidos em regimes totalitários. A análise, em específico, recai sobre o romance Lourenço Marques (2002), do escritor português contemporâneo Francisco José Viegas. $\mathrm{O}$ romance se apresenta como obra que perfaz esse caminho da constituição da memória e das identidades construídas a partir dela, inclusas no contexto pós-colonial que atingiu a África de língua portuguesa e pós-Revolução dos Cravos, em Portugal.

A importância dessas discussões considera dois elementos fundamentais: em primeiro lugar, trata-se da função social da literatura enquanto elemento questionador e perturbador da normatização; ou seja, a literatura, em suas mais variadas formas de manifestação, nunca é apenas literatura. Conforme indica João Alexandre Barbosa (2016), o fazer literário é capaz de "condensar essa fragmentação (os fragmentos da realidade) e fazer de tal forma que possamos ler como se fosse algo inteiriço aquilo que a realidade nos dá como estilhaços". O outro elemento diz respeito à importância de se compreender o universo global do qual fazemos parte a partir dos fragmentos da história recente que têm sido recolhidos e condensados na produção literária contemporânea e/ou pós-moderna.

Considerando como eixo norteador situações pós-traumáticas tanto do período ditatorial no Brasil e Portugal quanto da Guerra de Libertação nos países africanos de Língua Portuguesa, verifica-se na produção literária recente a "sedução da memória" em convergência ao que propõe Theodor Adorno (apud GAGNEBIN, 2006) quando chama a atenção para o fato de que menos importante é sacralizar a memória do que aprender (a partir da compreensão) com ela para evitar danos no presente e no futuro, bem como não permitir que essa situação traumática ocorra novamente.

O artigo se apresenta em dois tópicos: 1) diagnosticar, a partir da leitura e análise de narrativas contemporâneas de língua portuguesa (brasileiras, portuguesas e africanas) produzidas nas últimas duas décadas (19942014), a relação que se pode estabelecer com o passado histórico recente, efetivada em alguns romances exponenciais do período, tais como Lourenço Marques (2002), do português Francisco José Viegas, K. Relato de uma busca (2011), do brasileiro Bernardo Kucinski ou Um estranho em Goa (2000), do angolano José Eduardo Agualusa, entre outros; 2) a partir da realização de um levantamento dos romances editados no período destacado considerando a pertinência da publicação em relação aos tópicos de estudo, realizar a análise literária de obras que convergem para a temática abordada.

Desse modo, foi realizado um enquadramento quantitativo da presença da temática levantada para proceder às considerações sobre os elementos colhidos. Esse levantamento (realizado entre 2014 e 2015) demonstrou a presença das seguintes obras: 


\begin{tabular}{|c|c|c|c|}
\hline TÎTULO & AUTOR & $\begin{array}{c}\text { ANO } \\
\text { PUBLICAÇÃO }\end{array}$ & LITERATURA \\
\hline Lourenço Marques & Francisco José Viegas & 2002 & Portuguesa \\
\hline Manual dos Inquisidores & Antonio Lobo Antunes & 1998 & Portuguesa \\
\hline Os memoráveis & Lídia Jorge & 2014 & Portuguesa \\
\hline Deixem falar as pedras & David Machado & 2013 & Portuguesa \\
\hline Os bêbados e os sonâmbulos & Bernardo Carvalho & 1996 & Brasileira \\
\hline Amores exilados & Godofredo de Oliveira Neto & 2011 & Brasileira \\
\hline O irmão alemão & Chico Buarque & 2014 & Brasileira \\
\hline K. Relato de uma busca & Bernardo Kucinski & 2011 & Brasileira \\
\hline O esplendor de Portugal & Antonio Lobo Antunes & 1999 & Portuguesa \\
\hline O Mar em Casablanca & Francisco José Viegas & 2009 & Portuguesa \\
\hline Um estranho em Goa & José Eduardo Agualusa & 2001 & Angolana \\
\hline O vendedor de passados & José Eduardo Agualusa & 2004 & Angolana \\
\hline Predadores & Pepetela & 2007 & Angolana \\
\hline O céu e o fundo do mar & Fernando Bonassi & 2003 & Brasileira \\
\hline Prova contrária & Fernando Bonassi & 1999 & Brasileira \\
\hline O mar em Casablanca & Francisco José Viegas & 2009 & Portuguesa \\
\hline
\end{tabular}

Desse quadro, ${ }^{2}$ algumas das obras foram analisadas, em projetos de iniciação científica e trabalhos de conclusão de curso, por alunos sob minha orientação. Tal projeto pretendeu, portanto, analisar de que forma o romance contemporâneo em língua portuguesa apresenta a recuperação da memória recente, especialmente no que concerne aos fatos históricos e pós-traumáticos (abertura política nos estados totalitários, conflitos pós-colonias e ataques terroristas).

O recorte literário está centrado em narrativas (romances e contos) de autores brasileiros, portugueses, angolanos e moçambicanos publicadas nesse período e que tocam na questão central em discussão: a presença ou ausência da história recente em contextos locais e globais. A partir desse primeiro diagnóstico e seleção, a análise das narrativas convergiu para um estudo comparativo, entre duas ou mais obras, como forma de verificar como a história recente dos traumas sócio-históricos nas tramas literárias passa a ser configurada ou reconfigurada.

Passados vinte anos da queda do regime civil-militar no Brasil; quase o mesmo período da Guerra de Libertação nas Áfricas de Língua Portuguesa, da Revolução dos Cravos, em Portugal; e passada mais de uma década do ataque às Torres Gêmeas, é fundamental explorar a história e (re)inscrevê-la criticamente a partir da memória, dado que tais eventos traumáticos ressurgem nas Literaturas de Língua Portuguesa.

Acerca dessa constatação pode-se recuperar o estudo de Jeane Marie Gagnebin O que significa elaborar o passado?. Nele, a autora faz menção às considerações de Theodor Adorno nas quais evidenciava não a 
busca de uma sacralização da memória, mas sim a insistência no esclarecimento racional. Para o teórico alemão, o que importa, verdadeiramente, “[...] é a maneira pela qual o passado é tornado presente; se permanece na mera recriminação ou se se resiste ao horror através da força de ainda compreender o incompreensível" (ADORNO apud GAGNEBIN, 2006, p. 102). Compreender o incompreensível é a instauração da aprendizagem. Em momentos (pós) modernos, em que os lugares da memória edificam o passado para que o presente não se esqueça das atrocidades traumáticas, Andreas Huyssen (2009) assinala que os lugares de memória atuam como efeito compensatório em relação à perda dos meios de memória, e Walter Benjamin, em Sobre o conceito da História, também defende a importância de se "articular historicamente" o passado e não, apenas, descrevê-lo (1994). Observemos que, para o crítico, o verbo articular tem relações de sentido ético-políticas.

Assim, considerando a necessidade de articular, justamente do ponto de vista levantado pelos teóricos, a memória, a história e a literatura, se faz necessário ler e sobretudo refletir a partir da literatura contemporânea em língua portuguesa. Vale lembrar o período de distanciamento histórico impetrado na sociedade em relação aos momentos traumáticos que ocorreram (final de períodos ditatoriais, terrorismo gerado pelo ataque às Torres Gêmeas e as guerras de libertação) e sua absorção pela Literatura.

\title{
O FIO DA MEMÓRIA EM LOURENÇO MARQUES
}

\author{
A memória é frequentemente ridícula, \\ mas é o único instrumento que permite \\ imaginar histórias verdadeiras. \\ (Francisco José Viegas, do romance Lourenço Marques)
}

Lourenço Marques. Niassa. Pemba. Nampula. Lichinga. Beira. Maputo. Das províncias de Moçambique seria possível listar um itinerário e desenhar um mapa para uma viagem pelo norte do país. Esse desenho, traçado pela memória do passado e pelos rabiscos do presente de Miguel, personagem central do romance Lourenço Marques (2002), de Francisco José Viegas, permite ao leitor transitar pelas ruínas de um espaço e de um tempo que não existem mais. Publicado em Portugal com o título Lourenço Marques, no Brasil foi lançado pela editora Língua Geral e renomeado de A luz do Índico (2007). Se de um lado temos um título referencialmente espacial, de outro há uma referência imagética que atravessa a narrativa de Viegas. Autor reconhecido por seus romances policiais, cujo detetive Jaime Ramos tornou-se figura singular em duas das narrativas em enfoque: Longe de Manaus (2005) e O mar em Casablanca (2009), Viegas apresenta uma narrativa que sugere já em seu título, Lourenço Marques, um viés incômodo. 
Lourenço Marques era o antigo nome de Maputo, capital e maior cidade de Moçambique, e sugere, após a leitura do romance, a relação espaço-temporal entrevista a partir das lembranças de Miguel ao retornar a Moçambique depois de vinte e sete anos. A referência imagética é percebida no título da obra publicada, no Brasil, como A luz do Índico. Sem deixar de lado o referencial espacial - o oceano Índico que banha Moçambique a leste - focaliza-se, contudo, a luz. Nesse sentido, percebemos uma visada poética no título do romance quando nos deparamos com a afirmação de Miguel ao explicar essa luz, "Aquela luz perseguira-o como uma ameaça e como um aceno fatal, tão cortante como a lâmina do seu primeiro canivete, tão brilhante como os raios que se viam ao longe, sobre o mar da Inhaca, a partir da varanda da casa, ao fim da tarde." (VIEGAS, 2007, p. 128). A personificação da luz em ameaça ou aceno fatal, a perseguição ou a morte, sugere a importância que isso terá para o desenvolvimento da trama.

Por sua vez, o título original faz referência à província da atual Maputo e recupera um passado anterior à guerra civil de Moçambique e um presente marcado pela destruição deixada por ela. Elemento que atravessa constantemente a narrativa, a guerra é revista pelos olhares dos que ficaram e sofreram suas atrocidades e daqueles que fugiram e já não possuem identificação com ela. Entretanto, não se trata de um romance que pretenda - na esteira dos romances de formação - discutir a construção de uma identidade nacional em uma África pós-colonial.

O romance inicia com a descoberta do cadáver de Gustavo Madane, integrante da Frelimo, "Quinze anos de guerra, desmobilizado em 1993. Tratava o Samora por 'tu”' (VIEGAS, 2007, p. 17). O ex-combatente tornara-se figura de várias passagens pela polícia, a qual andava no seu encalço esperando algum deslize, especialmente, o capitão Domingos Assor, cujo passado, iremos descobrir no decorrer do romance, era marcado por mágoas pessoais em relação à Madane.

Uma ruptura corta a narrativa e conduz o leitor ao aeroporto de Maputo. A partir da utilização do discurso indireto livre, lembranças são evocadas pelo personagem que, ao descer do avião, ouve a voz do auto-falante citar: Pemba, Beira e Nampula. Ou as cidades do passado: Beira, Nampula e Porto Amélia. A voz e as cidades citadas são os fios que reacendem a memória do lugar e de um passado distante. Utilizando-se do fluxo de consciência, os pensamentos do personagem são apresentados num grande jorro de informações e lembranças que recuperam o passado colonial de Lourenço Marques, a Pérola do Índico.

Com o voo atrasado, o personagem dirige-se ao bar do aeroporto. Nesse momento, temos uma das cenas que corroboram nossa compreensão de um romance que, de forma dialética, apresenta o discurso dos clichês colonialistas, mas contrapõe, na afirmação de Mário César Lugarinho (2013), aos "discursos cristalizados a respeito da guerra e da independência dos países africanos", o discurso de Miguel. O personagem, descobriremos no andamento da narrativa, retorna a Maputo à procura de seu amor de adolescência, Maria de Lurdes. 
Em conversa com Daniel Venda, este lhe narra a transformação de Moçambique, à qual Miguel ouve com certo tom de descaso e ironia. É nesse momento que vemos reverberar um discurso que foge aos padrões críticos enaltecedores das nações que deixaram de ser colônias para demonstrar um universo estonteante. De acordo com Lugarinho, o que se apresenta é uma fala perturbadora que traz à tona um tipo de discurso “[...] que a urgência e as contingências da História recente teimam em empurrar para debaixo do tapete. O discurso de Miguel é, sobretudo, uma fala advinda de uma experiência íntima, irrepetível e fundadora" (LUGARINHO, 2013, p. 130).

Esse discurso pode ser percebido no capítulo em que Miguel encontra-se no aeroporto. Tal capítulo é bastante emblemático dentro das narrativas de Viegas por duas razões bastante significativas. Em primeiro lugar, pelo fato de a cena decorrer num espaço de trânsito: o aeroporto. Em segundo, porque esse espaço de trânsito que, a princípio, nada teria demais se fosse apenas uma transição entre a Europa e a África, é, também, espaço de memória. Ao iniciar o capítulo, percebemos a seguinte descrição:

Os ruídos do aeroporto não são os mesmos, mas ele recorda-se da voz dos altifalantes, há muito tempo, lembra-se da voz pomposa, irritante, com a gramática correcta e as vogais abertas: "Voo para Pemba com escalas na cidade de Beira e em Nampula". Melhor: voo DETA para Beira, Nampula e Porto Amélia. Para Porto Amélia. Foi o que os seus ouvidos ouviram, quisesse ou não. Voz traiçoeira. Colonial. Roupa colonial, arquitectura colonial, Bairro das Colónias, portugueses envergonhados excepto nos nomes, que eram grandiosos e evocavam oito séculos de História: Bairro das Colónias. Roupa colonial (VIEGAS, 2006, p. 22).

A passagem assinala a visão presente desse passado colonial que atravessa a capital moçambicana. O personagem Miguel torna-se emblema dessa memória que ainda está conectada ao passado colonial, como percebemos na introdução da passagem. O excesso de expressividade acerca do termo "colonial" indica, conforme Edward Said, o significado desse passado imperial dentro da realidade de milhões de pessoas, “[...] onde sua existência como memória coletiva e trama altamente conflituosa de cultura, ideologia e política ainda exerce enorme força” (SAID, 1995, p. 43).

À parte isso, o romance em destaque dialoga com a memória do império, da "Metrópole" com artifícios paradoxais: "portugueses envergonhados", mas que, ao mesmo tempo evocam os "oito séculos de histórias" e dominação portuguesa com orgulho patriótico. O pensamento onisciente diagnostica a vergonha da colonização exploratória, entretanto, a grandiosidade ainda se mantém no uso de nomes extensos e imperiais a nomear ruas e direções. Nomes que rememoravam os oito séculos. Ou seja, essa visão literária, explorada na voz de Miguel a dirigir-se a Venda, outro português em passagem por Moçambique, conduz ao posicionamento final que a passagem a seguir assinala: 
Não fales da guerra, Venda, que eu torturo-te: enquanto andavas aos tiros, a defender a Pátria, a dormir no mato e a apanhar malária, eu comia banana com leite condensado, bifes com molho de amendoim, bolo catembe, caranguejos à sofala, cuzcuz de Moçambique, matapá e mimini, ia à Pastelaria Princesa comer empadas e babás (VIEGAS, 2006, p. 27).

Essa passagem demonstra a relação entre Miguel e a guerra colonial. Como português que saiu de Moçambique, justamente no período mais crucial do período de descolonização, o personagem revela sua posição em relação ao período. Alicerçado dentro dos elementos que temos discutido - a memória recente e o esquecimento -, Miguel evidencia não só o outro lado dos que (não) participaram da luta pela independência de Moçambique, mas também, em contrapartida, os prazeres culinários (da fartura) diante daquele que correu risco de tiros, doenças e fome. Além disso, o fato de o personagem referir-se às comidas específicas da região africana recupera a questão da memória, o caso da madeleine em Marcel Proust, embora essa memória da Metrópole ocupe lugar opositivo à memória sentimental de Proust. A memória (recente) que o personagem recupera não se dá pela comida, mas sim pelo encontro com alguém que vivenciou - de perto - as atrocidades da guerra colonial em África e essa memória se contrapõe à sua, na Metrópole a degustar pratos (típicos da Madeleine) que lhe causavam outra lembrança.

É interessante notar essa ambivalência, ou melhor, contradição da memória da guerra para os dois personagens: Miguel e Venda. Tal condição pode ser compreendida como a própria construção identitária desses personagens:

[...] a guerra passou, e eu estive sempre nas tintas para a guerra, durante anos acumulei mensagens de todo o lado, nunca soube o que coleccionara, recados curtos de gente que queria reencontrar-se e nunca saberei explicar porque hão de querer reencontrar-se pessoas tão diferentes como estas, uma porque vivia na CUF e frequentava os Velhos Colonos onde praticava natação embora estudasse no Liceu Salazar, e dizia kanimambo pela memória e eu continuo jurando, xikuembo xanhaque, que ainda volto para minha terra, ambanine, amigo! tenho saudades, [...]. (VIEGAS, 2006, p. 27).

Como observamos na passagem acima, o posicionamento de $\mathrm{Mi}$ guel é bastante incisivo na visão bipartida que se pode ter diante da guerra, ao passo que ele não compreendia a necessidade do reencontro (ação já intermediatizada pela memória, busca-se "reeencontrar" algo ou alguém com quem já se teve contato e, por isso, a necessidade de outro ou novo encontro), especialmente, em se tratando de pessoas diferentes. E o que chama também a atenção é a contradição identitária desse personagem, ao transitar entre ser português e moçambicano. De um lado, os lugares que frequenta como colono e de outro as expressões linguísticas africanas: "kanimambo", "xikuembo xanhaque" e "ambanine". A primeira, além de significar "obrigado", é título de canção popular de Moçambique, de autoria 
de João Maria Tudela. A segunda, referente a uma exclamação religiosa, possivelmente, já que "xicuembo" refere-se a Deus, ser supremo, eterno e é antecedida do verbo "jurando" e à promessa de retorno vem ao encontro da despedida, "ambanine", Adeus!

O fluxo de memórias passadas e, em especial, a escolha das palavras do acervo linguístico moçambicano coloca o personagem Miguel em contato com seu passado. De forma paradoxal, o sentimento oscila entre a saudade e a tentativa de expressar certo descaso ("estar nas tintas"), porque a saudade vai operando, conforme o próprio personagem sinaliza, em sua memória a partir das "recordações como uma catástrofe". A catástrofe, nessa passagem da narrativa, passa a ser a confusão de espaços, tempos e saudade (não só de Miguel, mas de várias pessoas que tiveram de sair/fugir de Maputo, como Helena e Jorge Henrique que se entrelaçam no discurso verborrágico do personagem), que culmina na interjeição expressa por Miguel: "[...], um abraço maningue apertado, gente chunguila, sem canganhiça, que nomes eu te atirava à cara, Venda. Tchova, tchova! Tchova a memória" (VIEGAS, 2006, p. 28). A palavra tchova é tradicional em Moçambique e é o nome dado aos carrinhos de transporte empurrados à mão. Na expressão usada por Miguel, refere-se ao verbo tchovar, no sentido de empurrar. Empurrar ou conduzir essa memória para onde? E qual ou quais memórias?

[...] podiam ser estas memórias ou ser outras, [...] tu não sabes mas eu não venho à procura de uma vitória, não venho à procura de um combate que ficou por fazer, eu sou um derrotado, um dos vencidos, nunca poderia querer ganhar uma guerra em que não entrei, não me lembro do cheiro de pólvora, do cheiro dos mortos, do cheiro de merda, do cheiro do suor, do cheiro das feridas, do cheiro das queimaduras, do cheiro do pó, do cheiro dos outros homens. Lembro-me de uma cidade. Lembro-me de uma estrada. Lembro-me de um retrato. Lembro-me de uma tarde fantástica, lembro-me de ter dezasseis anos, talvez quinze, talvez oito ou sete, ou seis, ou de não ter idade, e lembro-me disso fazer sentido (VIEGAS, 2006, p. 28-9, grifos nossos).

A questão nessa memória relatada por Miguel, novamente, é o paradoxo. $\mathrm{O}$ fato de não se ter certeza sobre as memórias conduz à ênfase dada pelo personagem aos elementos da guerra colonial (cheiro de pólvora, dos mortos, da merda, do suor, das queimaduras). Pertencente à classe dos derrotados porque não foi à guerra, Miguel ao negar uma lembrança enfatiza sua importância pela memória do não. A sequência de frases negativas evoca uma memória sensorial. Para Dominique Veilton (citado por Michel Pollack), "[...] nas lembranças mais próximas, aquelas que guardamos recordações pessoais, os pontos de referência geralmente apresentados nas discussões são [...] de ordem sensorial: o barulho, os cheiros, as cores" (POLLAK, 1989, p. 11). Ou seja, ele pode afirmar não lembrar, mas enumera todos esses cheiros como se soubesse dessa lembrança. A ironia se dá na sequência. $\mathrm{O}$ uso do não afirma os aspectos de experiência traumática da guerra civil em Lourenço Marques, e essa não-lembrança, portanto, não faz 
sentido. É a lembrança enquadrada na cidade, na estrada, no retrato e de uma tarde fantástica numa idade incerta que faz sentido. O que o fragmento da fala de Miguel caracteriza é a necessidade de não se lembrar desse passado hostil e negro de mortes e motivação política. A ironia pretende demonstrar o silêncio sobre esse passado histórico na sociedade portuguesa. Além de irônico, o fragmento revela a condição melancólica como identidade de Miguel. A resignação de quem não foi à guerra e conforma-se (e ironiza) tal situação. Por isso, o verbo lembrar, que finaliza o fragmento, expõe o que poderíamos caracterizar como a tônica do romance.

A busca de Miguel por Sara, ou Maria de Lurdes, torna-se uma demanda, semelhante aos romances medievais, em que os cavaleiros saíam em busca do Graal ou de suas donzelas sequestradas. Mas, antes de ser em busca de alguém, agora o que se busca é um passado que poderia ter sido e não foi. Como o verso de Manuel Bandeira, em Pneumotórax, "A vida inteira que podia ter sido e que não foi", Miguel é o personagem de uma "narrativa memorialista sem ressentimentos ou saudades" que, ao transitar pelos lugares de Moçambique, relembra os lugares, as pessoas e as imagens de um passado que ficou congelado no tempo e que é sua identificação.

"Foi há muito tempo". A frase que repercute constantemente no romance de Francisco José Viegas sintetiza de forma muito clara o pensamento de Miguel. O passado já não existe mais, o tempo passou e Moçambique ficou em ruínas. Elas estão lá, mas apenas para lembrar que algo existiu e foi importante no passado para alguém. Esse alguém é desconhecido, assim como as lembranças que o marcam também são desconhecidas para os outros. Mas a memória, apesar de ridícula como o personagem afirma, possibilita transformar lembranças em fios da memória de si e que ajudam a atravessar esse labirinto perdido.

Lourenço Marques era o antigo nome da atual capital moçambicana, Maputo. A referência à atual Maputo recupera um passado anterior à Guerra Civil de Moçambique e um presente marcado pela destruição deixada por ela. Elemento que atravessa constantemente o romance, a guerra é revista pelos olhares dos que ficaram e sofreram suas atrocidades e daqueles que fugiram e já não possuem identificação com ela. Contudo, não se trata de um romance de formação ou ideológico com intenção de discutir a construção de uma identidade nacional em uma África pós-colonial. É possível pensar que se trata de um romance extemporâneo que vê o arruinamento das ex-colônias portuguesas pari passu ao arruinamento da metrópole, Portugal.

Nesse processo, o personagem transita pelos espaços de Moçambique, cidades que também já não possuem mais nem o nome nem a beleza que um dia Miguel conhecera. Esses espaços engendram um processo memorialístico no personagem que promove uma série de rememorações: de lugares, pessoas, imagens. Mas esse retorno ao passado não é visto por Miguel com ressentimento, saudade ou nostalgia. O que podemos perceber é uma sensação de fracasso ao tentar se recuperar um tempo perdido e que foi destruido. Os espaços percorridos por Miguel nessa demanda à Maria 
de Lurdes ou Sara reconstituem um tempo que já não existe mais, que se perdeu antes da guerra. Os novos nomes que surgem evidenciam esse deslocamento de espaço e tempo: Lourenço Marques agora é Maputo, Pemba é Porto Amélia, Maria de Lurdes é Sara.

Assim, Miguel segue transitando pelos lugares cujas pistas podem conduzir ao paradeiro de Sara. Essas pistas encaminham-no aos lugares visitados na infância e, portanto, a esse passado. Um passado colonial que é questionado dentro da estrutura narrativa a partir de uma visada ao mesmo tempo irônica e anticomplacente, como assinalamos em passagem anterior, como a referência às comidas tipicamente moçambicanas, "[...] eu comia banana com leite condensado, bifes com molho de amendoim, bolo catembe, caranguejos à sofala, cuscuz de Moçambique, matapá e mimini” (VIEGAS, 2006, p. 27).

Traço marcante nas narrativas de Francisco J. Viegas é a menção aos prazeres culinários, etílicos e paisagísticos. As lembranças, ao modelo proustiano da madeleine, são recuperadas ora pelas comidas, ora pelos cigarros ou charutos cubanos, ora pelas cervejas ou vinhos. No fragmento acima, as memórias culinárias se entrecruzam ao discurso político que não opera o sentido de resgate de um passado glorioso de lutas e batalhas pela independência de Moçambique. Ao contrário, o discurso de Miguel esboça o passado de um "derrotado", como ele adjetiva a si próprio, que se contrapõe à coragem de Venda. Enquanto este lutava bravamente, Miguel sucumbia aos prazeres culinários que, por sua vez, e ironicamente, representavam o país: bolo catembe, caranguejos à sofala, cuscuz de Moçambique, etc... É possível perceber, nessa digressão, que Miguel não luta pela pátria - ainda que essa não fosse sua -, mas sim degusta-a e deleita-se com esse prazer.

Conforme Edward Said, em Cultura e Imperialismo, “[...] pelas mais variadas razões, sente-se uma nova premência de entender o que permanece ou não permanece do passado, e essa premência se introduz nas percepções do presente e do futuro" (SAID, 1995, p. 38). Desse modo, esse outro olhar que a narrativa de Viegas lança ao passado colonial de Moçambique pode ser entrevisto, também, na passagem em que Domingos Assor se apresenta a Miguel:

Domingos. E Assor. Exactamente como lhe digo. E macua, naturalmente. Do Niassa, ou de Nampula. Em Moçambique só se sabe a origem da família até à segunda geração. Antes, é tudo há muito tempo. Os europeus gostam das nossas histórias sobre a memória, as raízes, o passado, as árvores mortas. Temos muitos escritores que vivem disso, mudam a ortografia para parecer mais exótico, falam da grande bondade do homem africano e das raízes do mundo. É um produto turístico, como os brinquedos de madeira dos miúdos ali do Ferroviário, na MacMahon: ganha-se alguma coisa, vai-se sobrevivendo (VIEGAS, 2007, p. 157).

Um discurso sobre a memória que discute essa construção memorialística por parte do colonizador: os europeus. A memória, o passado e as raízes são um "produto turístico"; tornaram-se, em tempos de globali- 
zação, um produto que passa a ser vendido nos mercados públicos, como as lembrancinhas "estive aqui e lembrei de você".

A expressão "é tudo há muito tempo", que repercute constantemente no romance através das falas ou pensamentos de Miguel ou dos demais personagens, sintetiza de forma muito clara esse passado que já não existe mais e que, no entanto, é recuperado pelas ruínas e pelos novos nomes de Moçambique e regiões. As ruínas estão lá para lembrar que algo existiu e foi importante no passado para alguém. Servem, também, para indicar traços de um passado que se quer presentificar, mas, dado à impossibilidade de nitidez da memória, não consegue atingir sequer o objetivo mais explícito: encontrar Maria de Lurdes ou o assassino de Gustavo Madane. Talvez porque não seja esse o objetivo real, e sim, um acerto de contas com o passado que destruiu não apenas espaços geográficos, mas também memórias pessoais e coletivas.

É por isso que insurge, nas reflexões do inspetor Jaime Ramos, em O mar em Casablanca (2009), a ruína do império e o passado colonial que vem acertar contas com ele também. Nesse romance,

[...] cada inquérito persegue-te com o cheiro de África e os que dizem "ah, o cheiro de África", mas nunca estiveram diante dos teus cheiros de África - o da merda, o da pobreza, o do lixo, o das coisas apodrecendo ao ar livre nos subúrbios, o dos mortos acumulados no mato, esquecidos, rendidos. Merda para África, "adeus Guiné, serás sempre Portugal". E quase quarenta anos depois de ouvires essa canção "adeus Guiné, serás sempre Portugal”, quarenta anos depois estás no hospital, sentado diante da vida inteira, e aparece-te Angola de novo, e outros combatentes, e o cheiro da África, a ladainha do colonizador e do colonizado, o da África toda, embora África não seja a terra prometida (VIEGAS, 2009, p. 120).

Poder-se-ia dizer que o passado ensaia uma recuperação a partir da memória. Contudo, o que podemos observar é um amortecimento, tanto de Jaime Ramos, quanto do país que representa Portugal. E, à semelhança da fala de Domingos Assor mencionada anteriormente, já não se pode mais crer em uma África enquanto "árvores mortas" ou "terra prometida", porque esta há muito tempo deixou de existir. Apenas os discursos da memória procuram dar sentido às pistas desses territórios e identidades arruinados.

A tese IX de W. Benjamin em Sobre o conceito de história é mais uma das passagens significativas do filósofo acerca do conceito de ruína. $\mathrm{O}$ anjo da história, que tem o rosto dirigido para o passado, vê a catástrofe. Essa catástrofe está ancorada às ruínas dispersas sobre nossos pés e "esse amontoado de ruínas cresce até o céu" (BENJAMIN, 1994, p.226). As ruínas podem ser compreendidas como signos, como algo que permanece para lembrar de algo que ali existiu e, portanto, guarda o sentido de algo que se desfez, que ruiu. Este signo, ou imagem revela-se como forma de petrificação dos acontecimentos que atravessaram a história, ao mesmo 
tempo em que se mostra como prognose do futuro. Basta lembrarmos das ruínas de Hiroshima e Nagasaki. Os restos desmoronados, como vimos nos romances de Francisco José Viegas, convergem nessa imagem do anjo de Benjamin. O progresso enquanto futuro d/nesses espaços (a luta pela independência das ex-colônias portuguesas) é feito das ruínas e escombros que continuam ali para lembrar que, ironicamente, melancolicamente ou criticamente, não se pode cair no esquecimento para evitar novas catástrofes.

\section{REFERÊNCIAS BIBLIOGRÁFICAS}

BARBOSA, João Alexandre. Literatura nunca é apenas literatura. Disponível em: http://www.crmariocovas.sp.gov.br/lei_a.php?t=013. Acesso em: 22 de agosto de 2016.

BENJAMIN, Walter. Magia e técnica, arte e política. Tradução Sérgio Paulo Rouanet. São Paulo: Brasiliense, 1997.

. Rua de mão única. Tradução Rubens Rodrigues Torres Filho e José Carlos Martins Barbosa. São Paulo: Brasiliense, 2009.

GAGNEBIN, Jean Marie. Lembrar escrever esquecer. São Paulo: Editora $34,2006$.

LUGARINHO, Mário César. Uma nau que me carrega: rotas da literariedade em língua portuguesa. Manaus: UEA Edições, 2013.

POLLAK, Michael. Memória, Esquecimento, Silêncio. Revista Estudos Históricos. Rio de Janeiro, v. 2, nº 3, p. 3-15, 1989.

SAID, Edward. Cultura e imperialismo. Tradução Denise Bottman. São Paulo: Companhia das Letras. 1995.

VIEGAS, Francisco José Viegas. A luz do índico. Rio de Janeiro: Língua Geral, 2007.

. Lourenço Marques. 6 ed. Porto: Asa Editores, 2006

. O mar em Casablanca. Porto: Porto Editora, 2009.

Recebido para publicação em 06/10/2017

Aprovado em 08/02/2018

\section{NOTAS}

${ }^{1}$ Docente de Literatura do Departamento de Letras e do Programa de Pós Graduação em Letras da Universidade Estadual do Centro Oeste (UNICENTRO), Paraná. Doutora em Estudos Comparados de Literaturas de Língua Portuguesa (USP). E-mail: adenizeafranco@gmail.com

2 Evidentemente que o quadro contempla apenas uma parte das narrativas que discutem a questão da memória recente em países de língua portuguesa marcados por regimes totalitários. Ressalto aqui que o projeto, por sua amplitude, contou com um número pequeno de integrantes e, com isso, a identificação e análise deteve-se apenas em parte deles. 